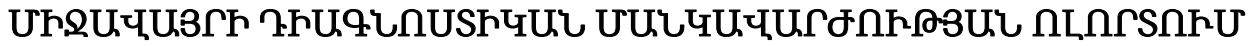

ヒqUน3นᄂ 9. 9.

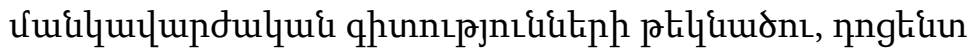

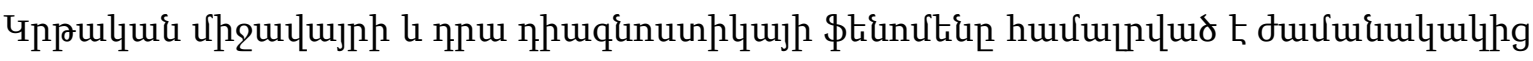

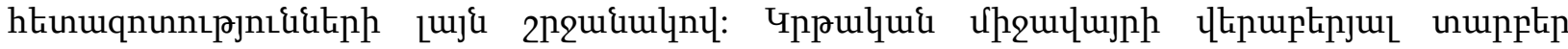

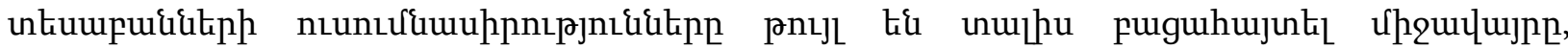

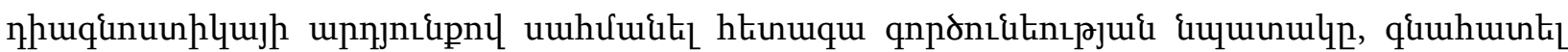

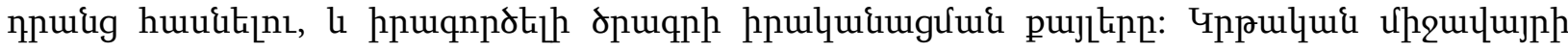

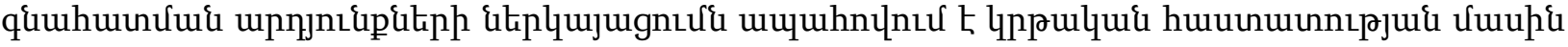

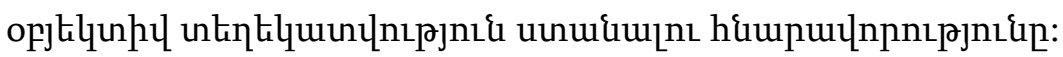

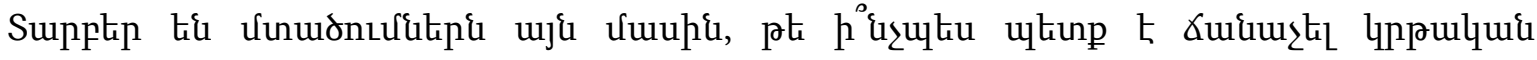

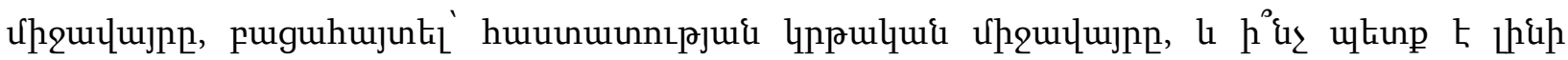

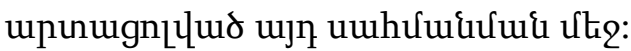

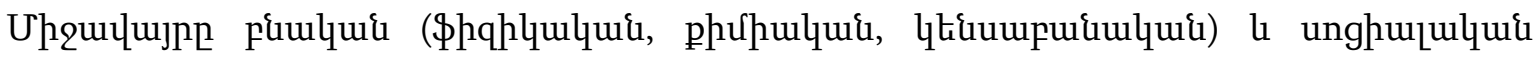

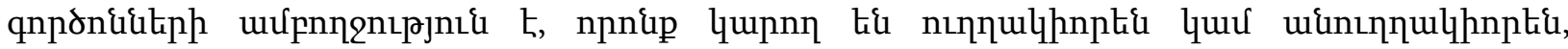

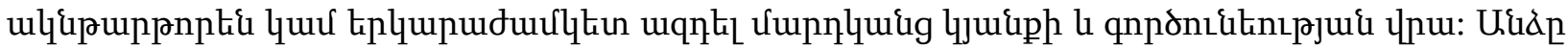

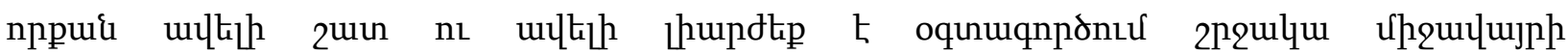

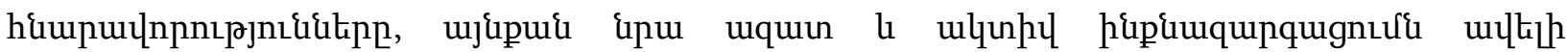

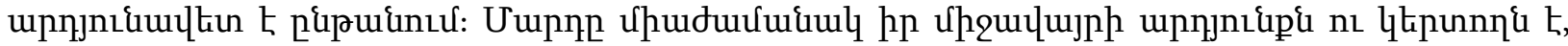

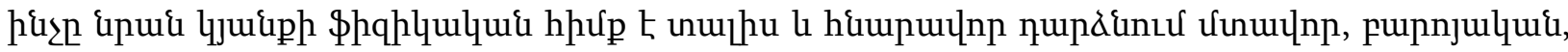

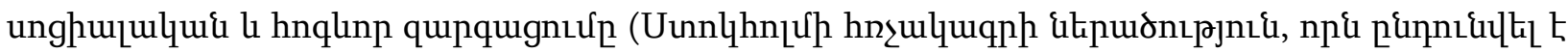

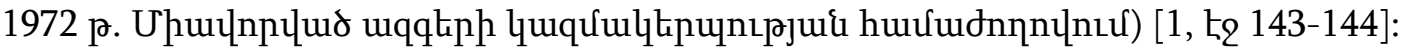

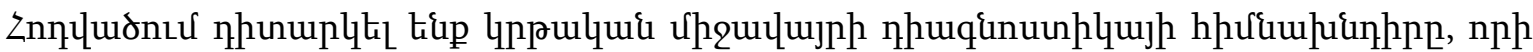

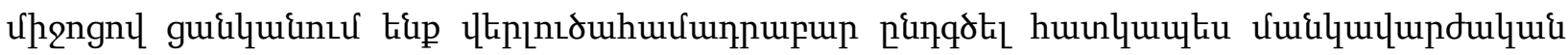

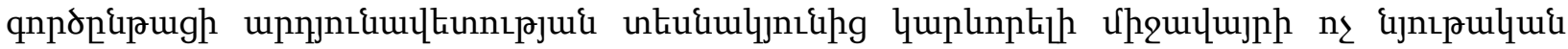

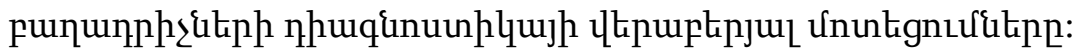

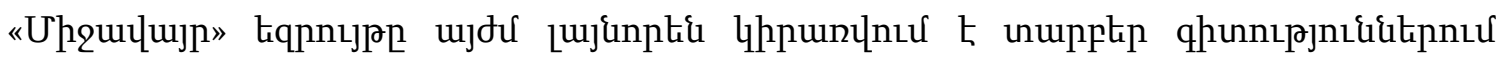

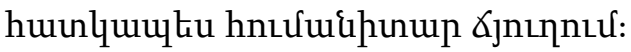

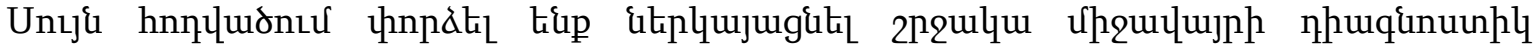

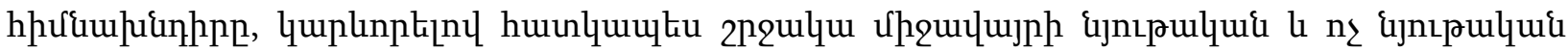

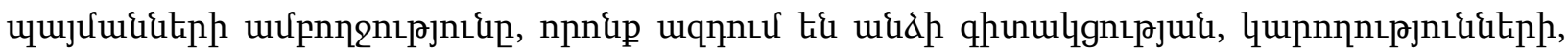




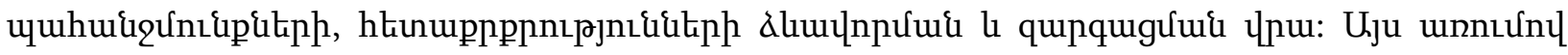

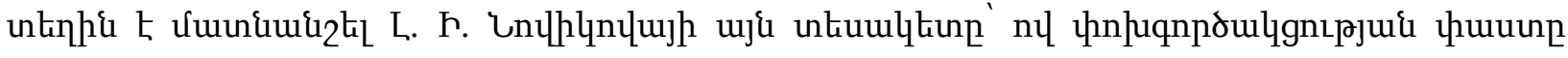

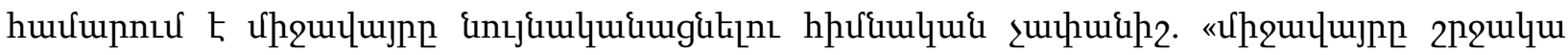

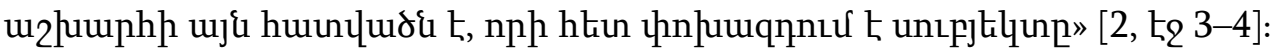

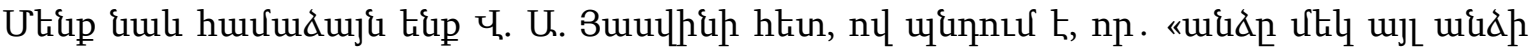

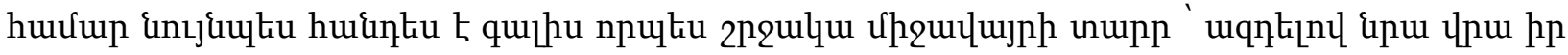

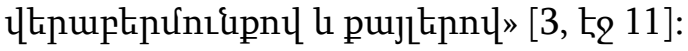

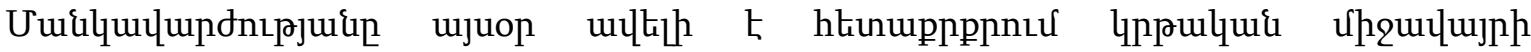

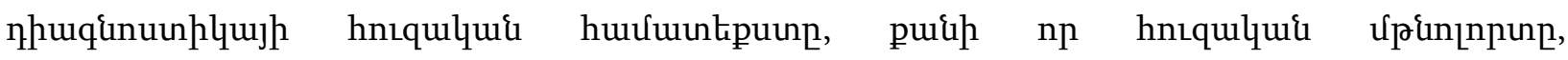

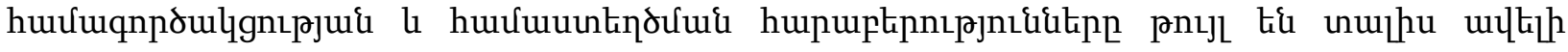

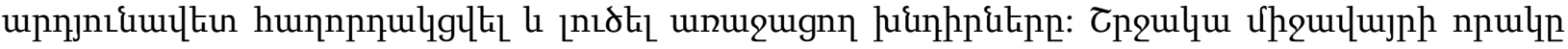

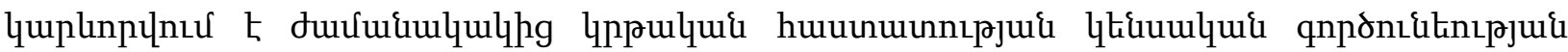

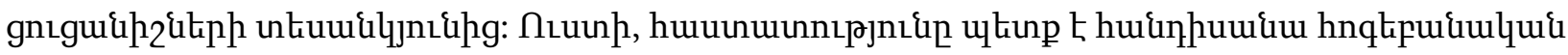

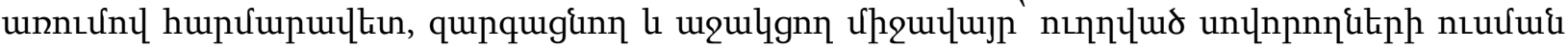

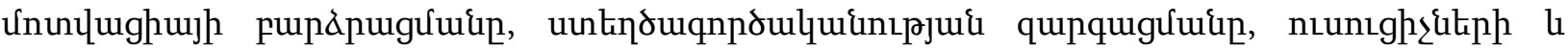

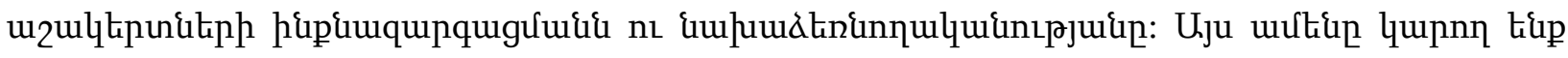

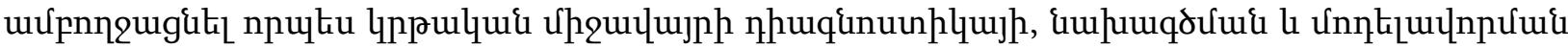

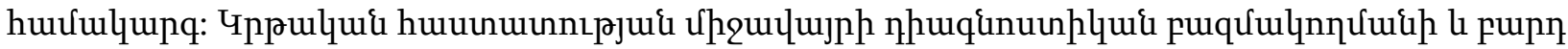
huưulqunqtih kplnujp k:

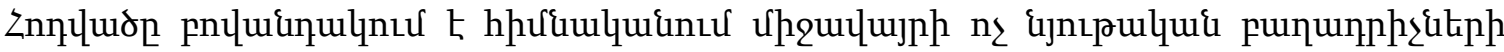

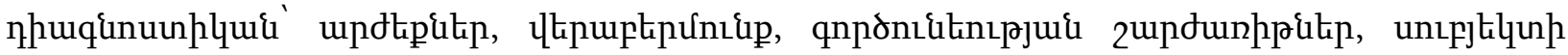

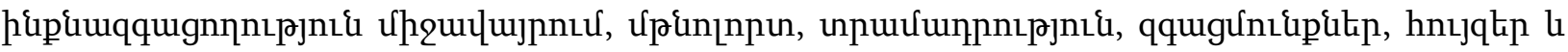
uj[L:

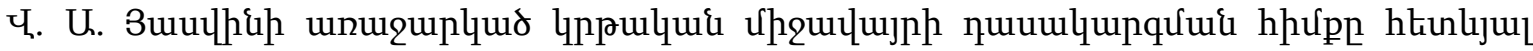

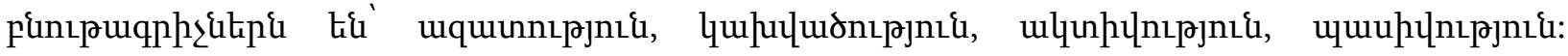

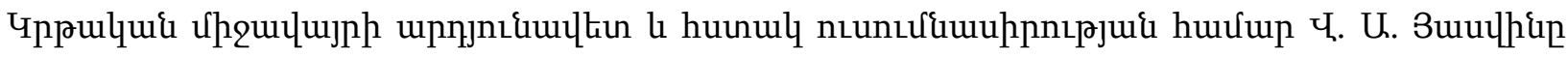

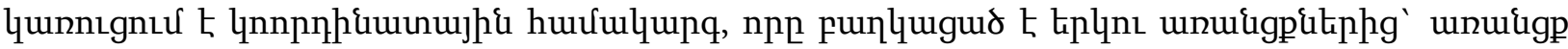

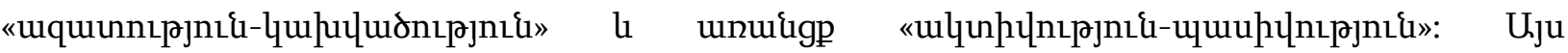

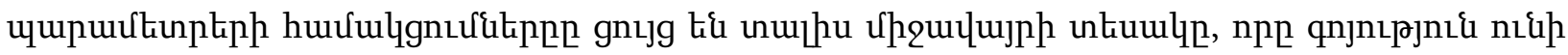

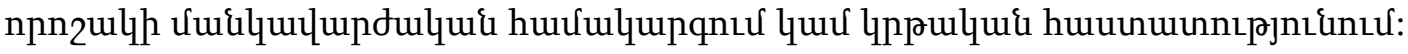

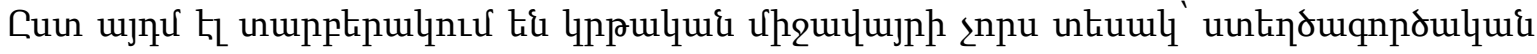

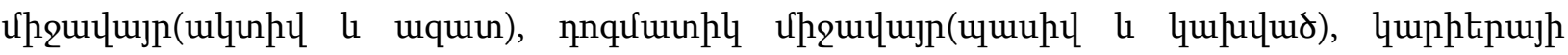

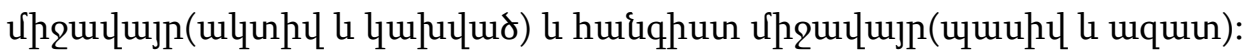




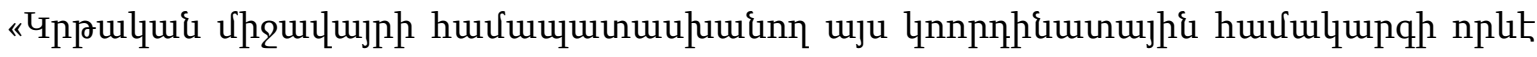

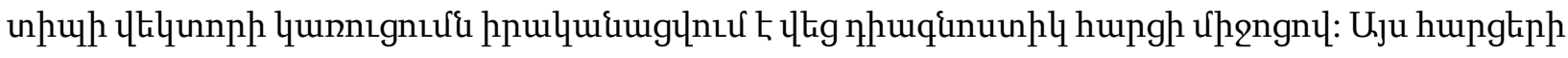

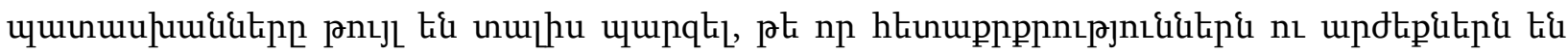

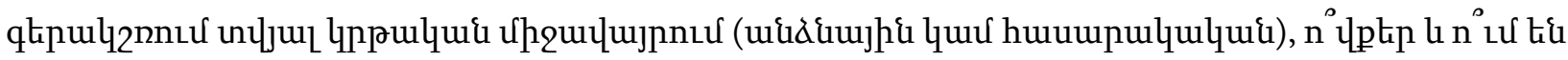

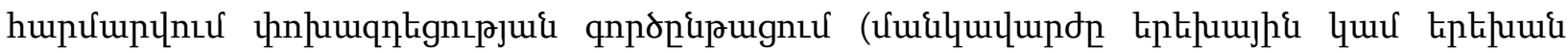

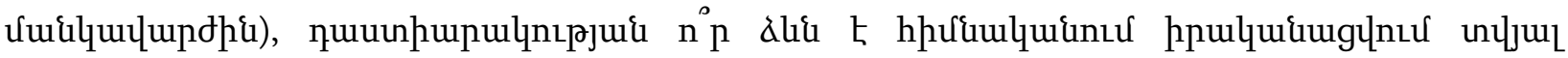

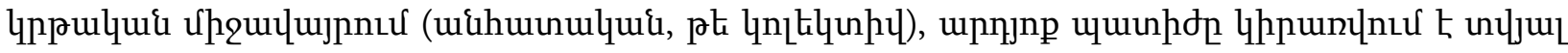

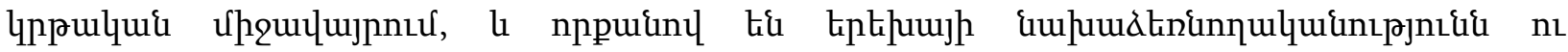

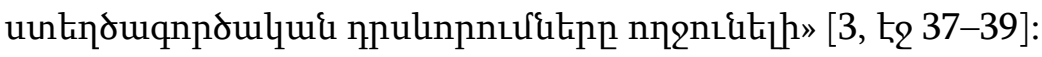

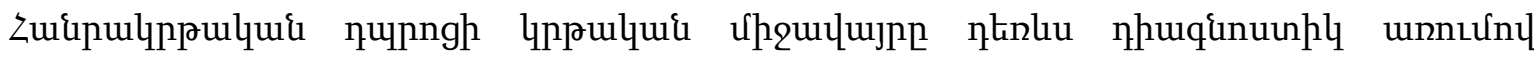

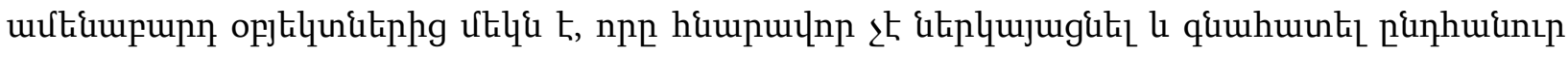

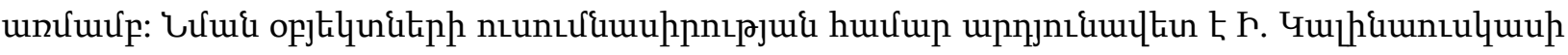

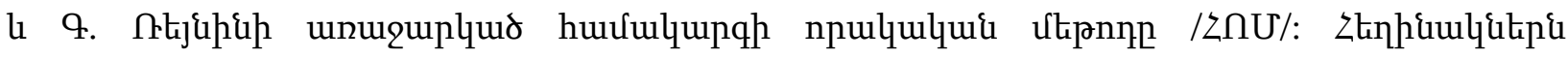

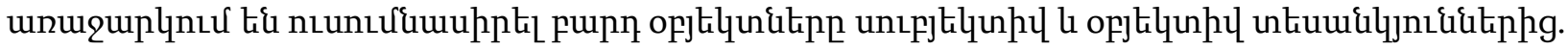

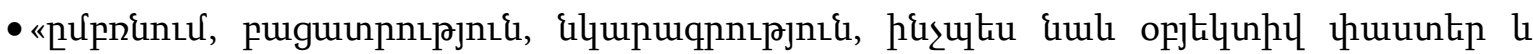

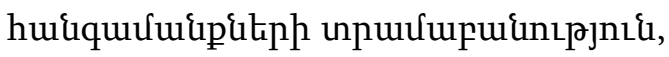

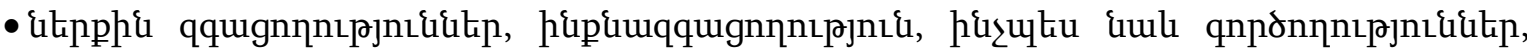

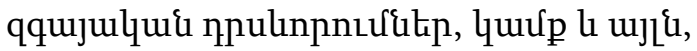

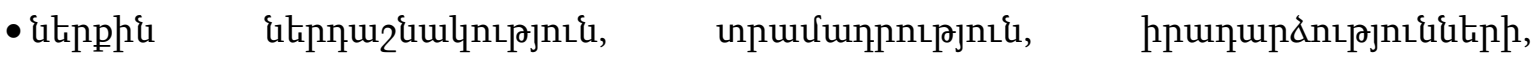

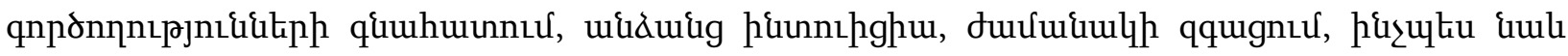

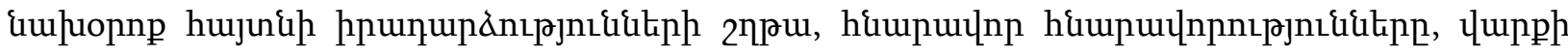

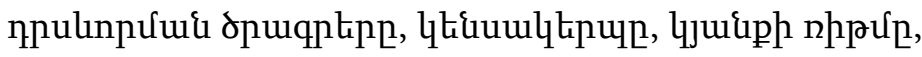

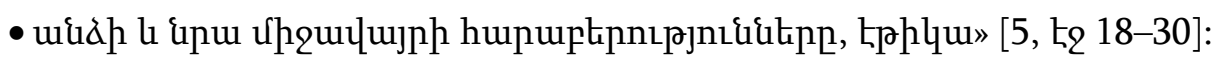

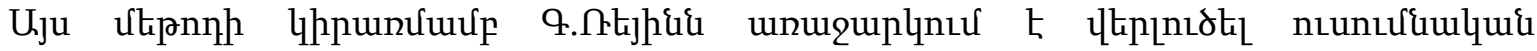

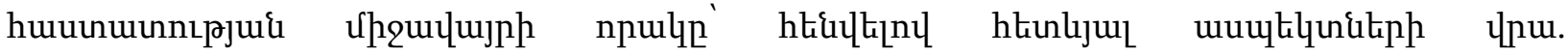

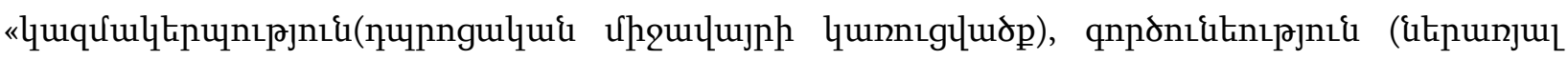

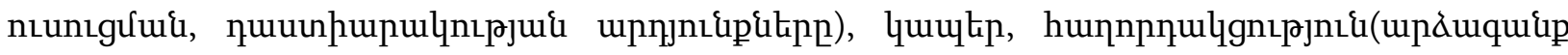

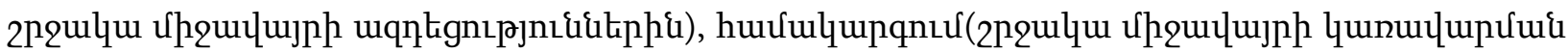
huvululupq)»[5, tq 18-30]:

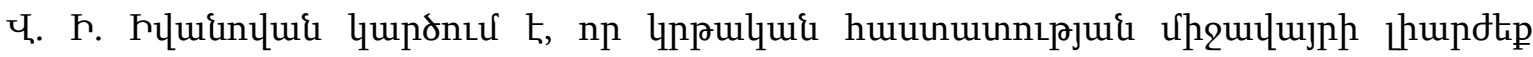

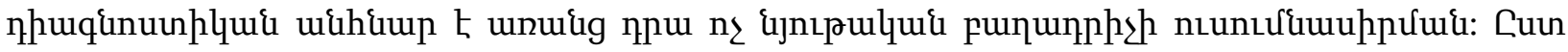

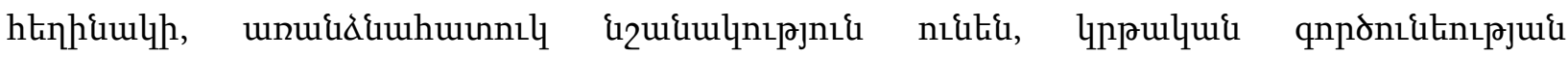

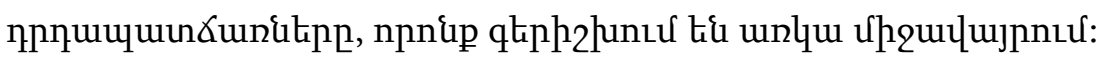




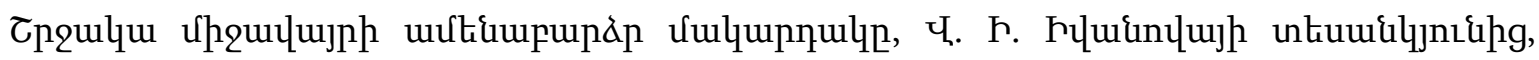

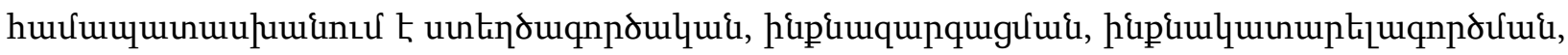

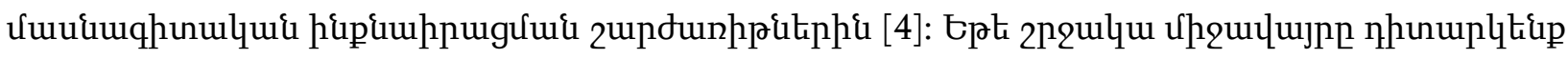

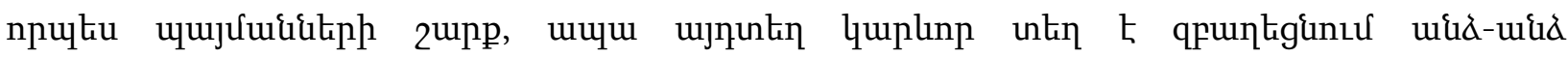

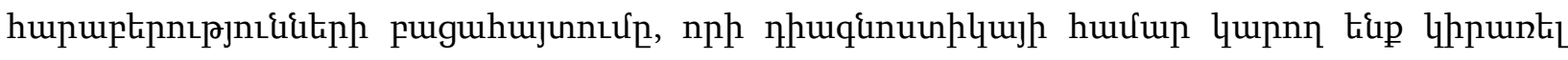

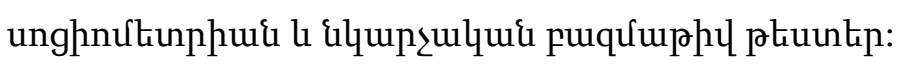

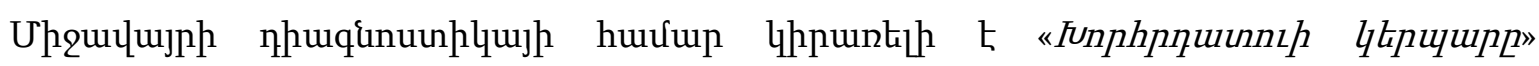

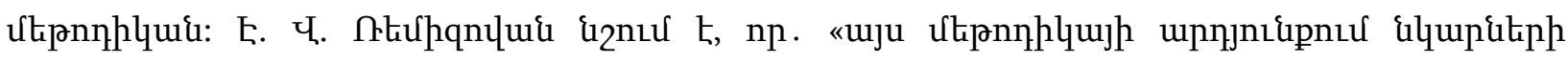

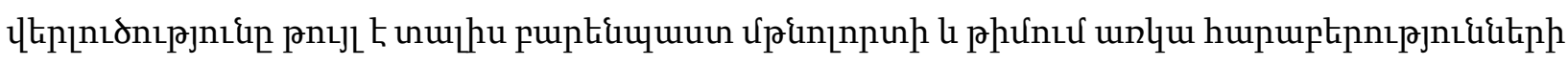

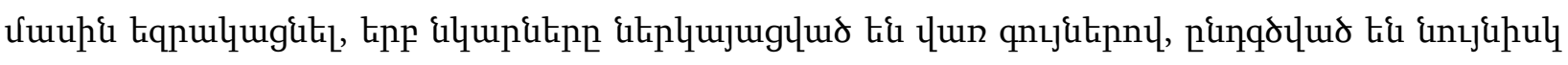

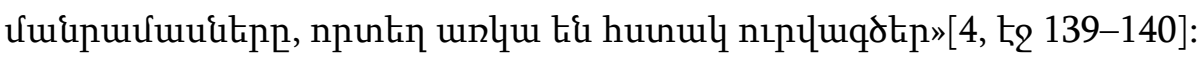

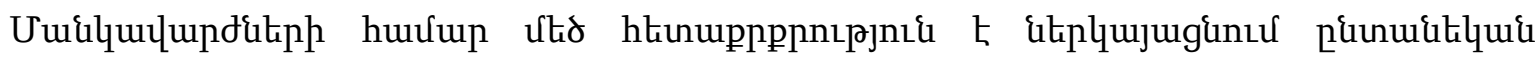

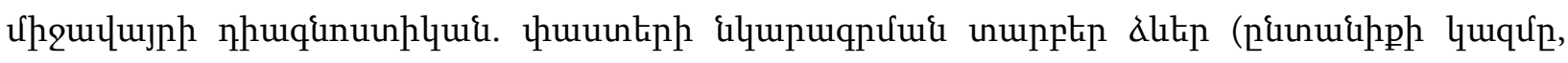

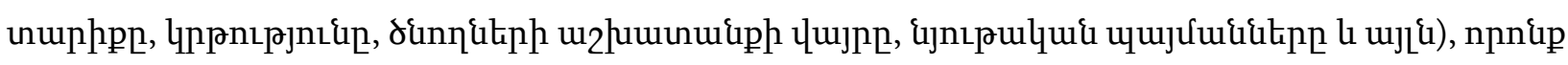

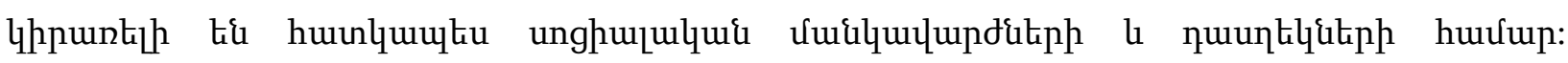

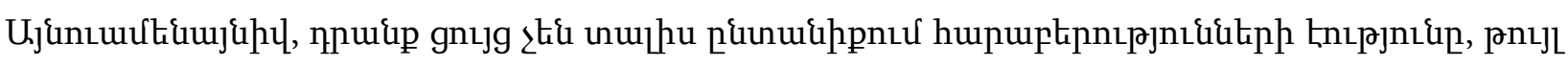

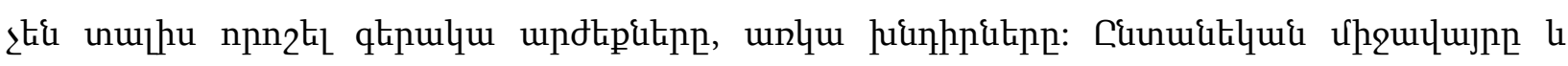

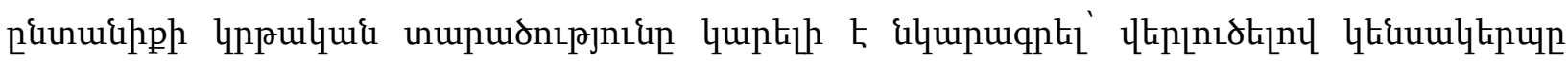

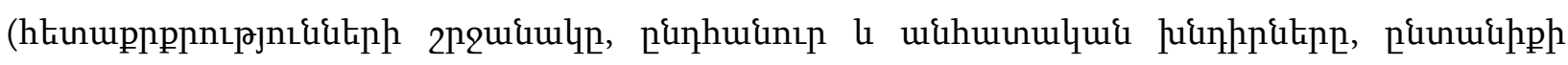

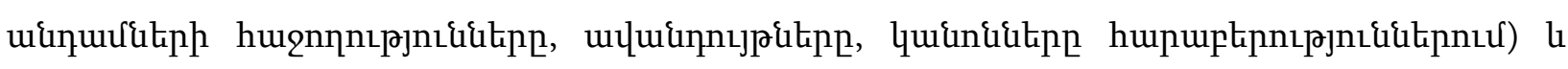

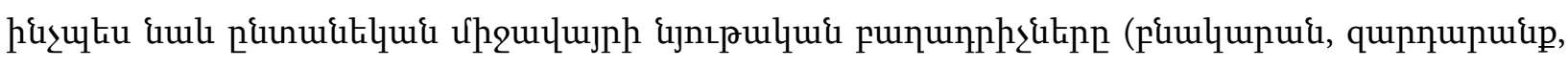

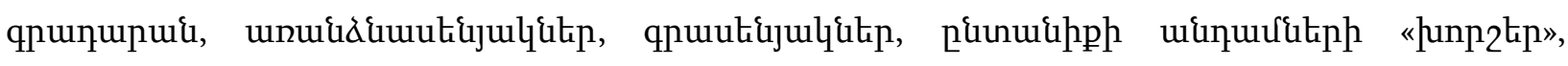

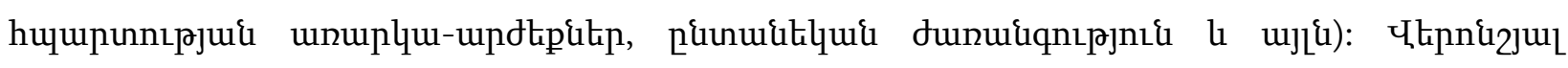

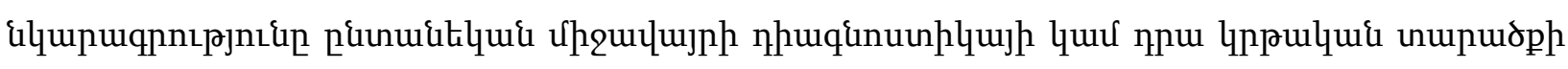

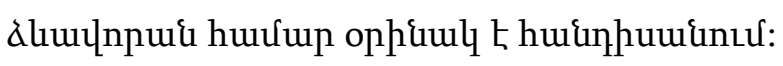

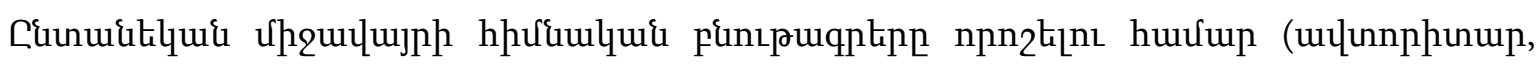

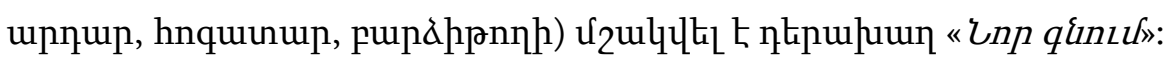

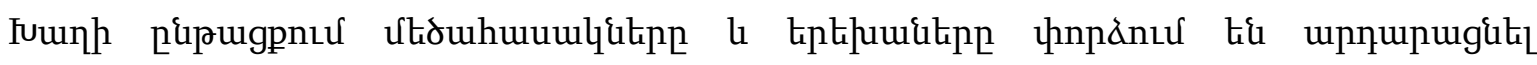

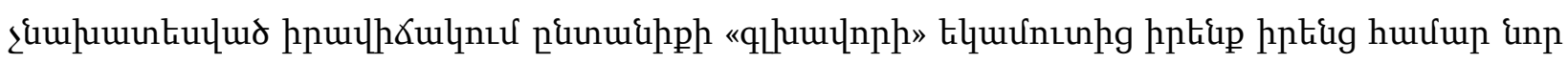

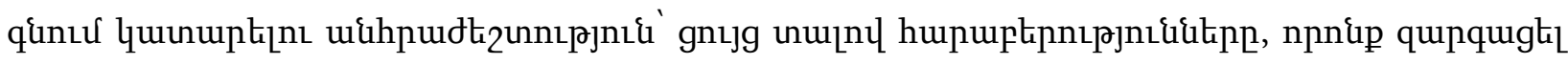

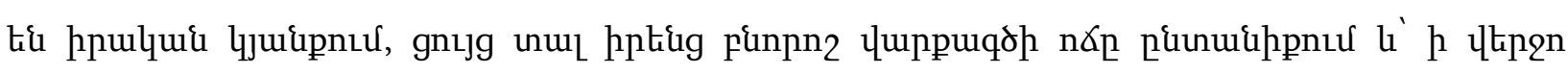

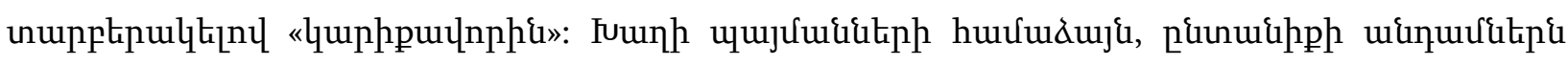

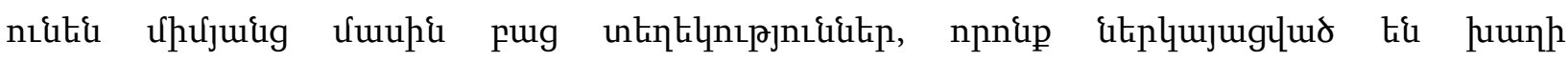




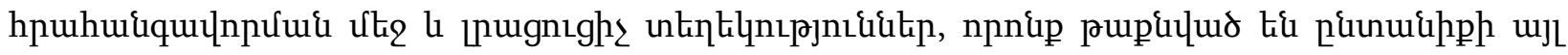

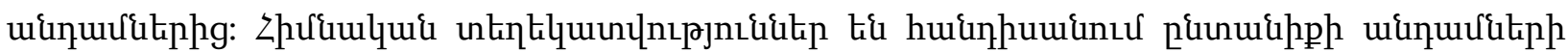

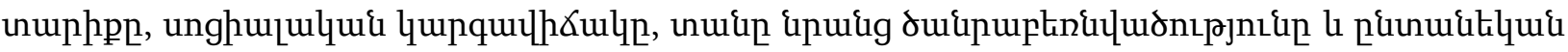

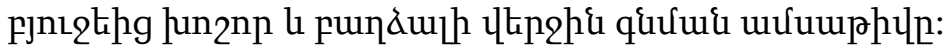

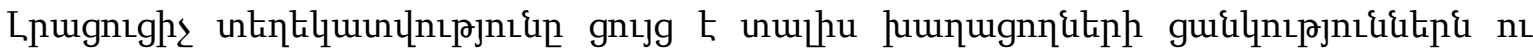

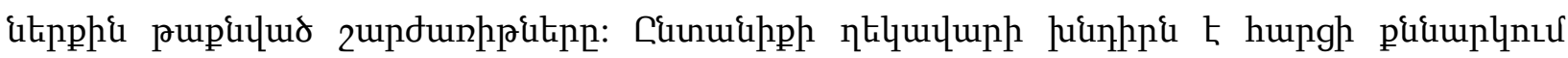

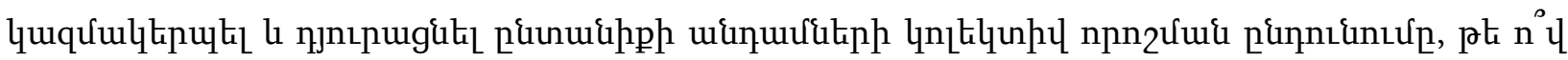

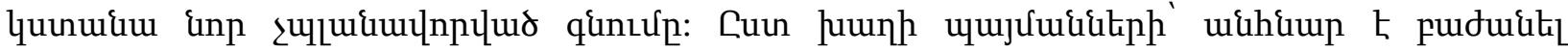

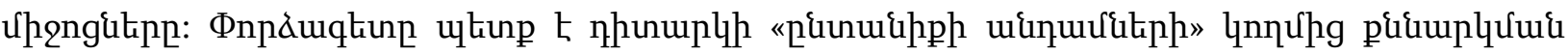

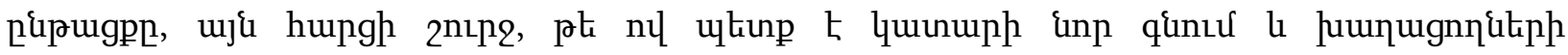

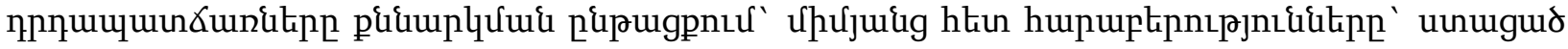

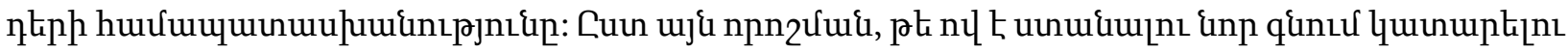

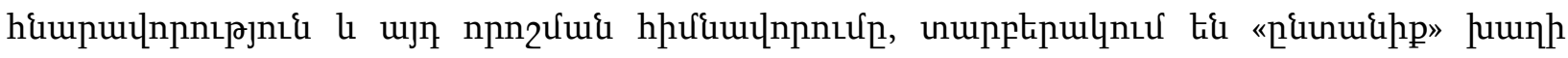

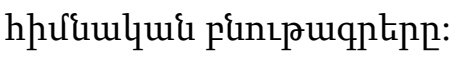

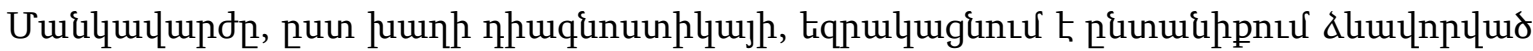

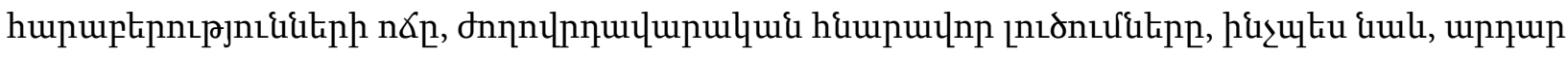

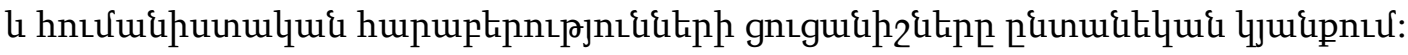

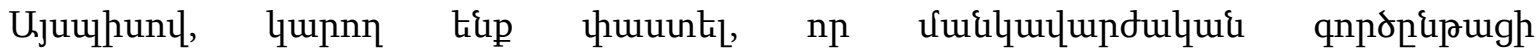

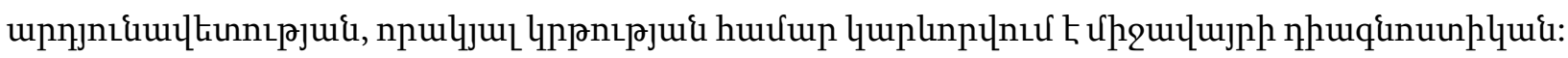

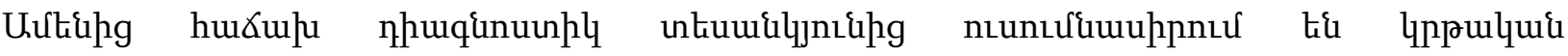

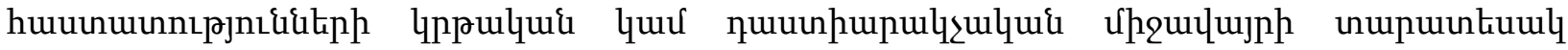

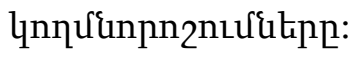

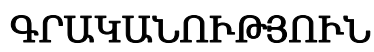

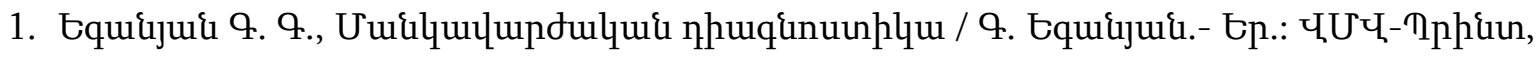
2020.- 232 tq:

2. Новикова Л. И. Школа и среда. М., 1985.

3. Ясвин В. А. Образовательная среда: от моделирования к проектированию. М., 2001.

4. Иванова В. И. Акмеологическая концепция формирования образовательной среды подготовки специалистов. Автореф. дисс. ... д-ра пед. наук.

5. Рейнин Г. Тайны типа. Модели. Группы. Признаки. М., 2009.

6. URL: http://dissers.ru/avtoreferatidissertatsii-pedagogika/a449.php.: 


\section{ENVIRONMENTAL DIAGNOSTICS IN THE FIELD OF PEDAGOGY}

The paper deals with the problem of diagnostics of the environment of the educational organization. It discusses existing pedagogical approaches to the diagnosics of intangible components of the environment and also gives examples of employing various methods of diagnostics of the environment in social and educational activities. The paper comes to a conclusion about the necessity of integrating ideas of pedagogical science and practice with the aim of improving the quality of the environment of educational institutions.

Keywords: Social and pedagogical activity, environment, educational environment, educational environment diagnostics, vector environmental methods, drawing tests, family environment, role play. 